\title{
Penyuluhan Hukum : Pencegahan Kenakalan Remaja Di Desa Ngujung Kecamatan Maospati Kabupaten Magetan
}

\author{
Moch. Juli Pudjiono ${ }^{1}$, Bambang Sukarjono ${ }^{2}$, Hery Sumanto ${ }^{3}$ \\ ${ }^{\text {I}}$ Fakultas Hukum, Universitas Merdeka Madiun, Jl.Serayu No.79, Madiun, 63133 \\ E-mail: julipudjiono@unmer-madiun.ac.id \\ ${ }^{2}$ Fakultas Hukum, Universitas Merdeka Madiun, Jl.Serayu No.79, Madiun, 63133 \\ E-mail: bambangsukarjono@unmer-madiun.ac.id \\ ${ }^{3}$ Fakultas Hukum, Universitas Merdeka Madiun, Jl.Serayu No.79, Madiun, 63133 \\ E-mail: herysumanto@unmer-madiun.ac.id
}

\begin{abstract}
This service aims to provide an understanding of juvenile delinquency problems. By using legal counseling methods. Location of community service in Ngujung Village, Maospati Subdistrict, Magetan District. Based on the results of the discussion show that adolescence is a period where an individual experiences a transition from one stage to the next and experiences changes in both emotions, body, interests, behavioral patterns, and also full of problems. While Juvenile delinquency (juvenile delinquency) is malicious behavior, or crime / delinquency of young people is a social pathology in children and adolescents caused by a form of social neglect, so they develop deviant forms of behavior. For this reason, efforts to prevent juvenile delinquency can be done, among others: (1) Parents must pay more attention, supervision, and affection to children and parents must open two-way communication (listening and open) to children, (2) Giving limits on freedom, (3) Providing religious education to adolescents, (4) Teaching adolescents not to be easily influenced by negative relationships, (5) Providing positive activities to adolescents so that adolescents are busy and do not have time to do things negative things and (6) Providing knowledge about laws that regulate juvenile delinquency and sanctions.
\end{abstract}

Keywords—: Extension of Law; Juvenile Delinquency.

\section{PENDAHULUAN}

Masa remaja sering disebut proses pembentukan diri menjadi dewasa. Proses perubahan ini menuju kepada proses pematangan kepribadian yang penuh dengan pemunculan sifat-sifat pribadi yang sesungguhnya yang harus berbenturan dengan persoalan dari luar. Benturan inilah yang menimbulkan persoalan bagi remaja yang lemah mental, jiwa dan rohaninya, terkadang diwujudkan dengan suatu tindakan yang menyimpang yang sering disebut kenakalan remaja yang digolongkan dalam tindakan amoral, perkelahian antar remaja sampai tindak kejahatan.

Kenakalan remaja bukanlah merupakan suatu masalah yang baru muncul kepermukaan, tetapi masalah ini sudah ada sejak berabad-abad yang lampau dan menjadi persoalan yang aktual hampir di semua negara-negara di dunia, termasuk di Indonesia. Sebagaimana yang dikatakan oleh Romli Atmasasmita ${ }^{1}$ bahwa : "Kenakalan adalah suatu tindakan yang dilakukan oleh seorang anak yang dianggap bertentangan dengan ketentuan-ketentuan hukum yang bcrlaku di suatu negara yang oleh masyarakat itu sendiri dirasakan serta ditafsirkan sebagai perbuatan tercela".

Dari pengertian di atas dapat disimpulkan bahwa kenakalan merupakan suatu pengertian yang memuat segi-segi juridis maupun segi-segi sosiologis. Selanjutnya pengertian remaja dikemukakan oleh Zakiah Daradjat ${ }^{2}$ adalah: Remaja adalah usia transisi. Seseorang individu telah meninggalkan usia kanak-kanak yang lemah dan penuh ketergantungan, akan tetapi belum mampu ke usia yang kuat dan penuh tanggung jawab, baik terhadap dirinya maupun terhadap masyarakat. Banyaknya masa transisi ini tergantung kepada keadaan dan tingkat sosial masyarakat dimana dia hidup. Semakin maju masyarakat semakin panjang usia remaja karena ia harus mempersiapkan diri untuk menyesuaikan dalam masyarakat yang banyak syarat dan tuntutannya".

Berdasarkan pada kenyataan ini, sangat dituntut peranan keluarga ataupun orang tua untuk mengarahkan anak-anak remaja, sehingga tidak terjerumus kenakalan remaja. Disamping itu masyarakat juga harus turut berpartisipasi untuk mencegah timbulnya kenakalan remaja karena adaiah kewajiban setiap orang untuk ikut berpikir dan bertindak mengarahkan kehidupan para remaja untuk menjadi orang yang berguna bagi bangsa dan negara. Dalam hal ini turut pula peranan pihak kepolisian sebagai salah satu instansi yang paling berwenang dalam mengatasi dan mengantisipasi kenakalan remaja.

\footnotetext{
${ }^{1}$ Atmasasmita, Romli. 1993. Problem Kenakalan Anak-anak Remaja (Yuridis Sosial Kriminologi), Armico, Bandung, 87

${ }^{2}$ Darajat, Zakiah. 2014 .Problema Remaja diIndonesia, Bulan Bintang, Jakarta : Bulan Bintang, hal 35
} 
Website : http://dayamas.unmermadiun.ac.id/index.php/dayamas

\section{METODE PENYULUHAN HUKUM}

Metode yang digunakan dalam pelaksanaan pengabdian kepada masyarakat ini menggunakan metode penyuluhan hukum, Metode Penyuluhan adalah cara yang sistematis untuk menyampaikan pesan agar dapat terjadi perubahan sehingga sasaran mengetahui dan mau serta mampu dalam menerapkan substansi materi yang disampaikan.

Secara sosiologis kegiatan penyuluhan hukum adalah salah satu upaya yang harus dilakukan dan mendapat dukungan segenap warga masyarakat agar hukum dapat berfungsi sebagaimana mestinya, sehingga hukum dapat memberikan manfaat (uttility) bagi kehidupan masyarakat, bangsa,dan negara.

Sebagaimana pendapat Soerjono Soekanto bahwa: tujuan utama penyuluhan hukum adalah, agar warga masyarakat memahami hukum yang berlaku, sehingga hukum tersebut melembaga dan bahkan menjiwai warga masyarakat bersangkutan. ${ }^{3}$

Untuk sampai pada tingkat kesadaran hukum masyarakat, maka segi manfaat atau kegunaan hukum haruslah betul-betul dapat dipahami oleh setiap warga masyarakat. Keadaan sebaliknya dimana media informasi yang cenderung memperkenalkan hukum pada masyarakat sebagai sesuatu yang menakutkan, sesuatu yang merepotkan, dan sesuatu yang hanya ideal dalam norma tapi tidak konsisten dalam pelaksanaannya, haruslah dinetralisir dengan pembentukan suatu kondisi dimana masyarakat menjadi berpersepsi yang baik atau menguntungkan tentang hukum. Dengan kegiatan penyuluhan hukum yang berhasil membangun opini masyrakat kearah yang positif maka persepsi masyarakat yang negatif terhadap hukum diharapkan dapat berkurang, sehingga dapat diganti dengan persepsi positif yang berpengaruh baik terhadap hukum. Bila kondisi ideal seperti ini terbentuk harapan selanjutnya dapat memunculkan semangat yang membentuk pengakuan atas kemanfaatan hukum bagi kehidupan segenap warga masyarakat.

\section{III.PEMBAHASAN}

\section{A. Profil Desa Ngujung Kecamatan Maospati Kabupaten Magetan}

Desa Ngujung merupakan salah satu desa yang berada di sebelah timur wilayah Kabupaten Magetan yang berada di Kecamatan Maospati. yang memiliki luas wilayah 226,80 ha. Dengan jumlah penduduk 2895 orang yang terdiri dari 1399 lakilaki dan 1496 perempuan.

Secara administrasi pemerintahan wilayah desa Ngujung mempunyai batas wilayah yang telah ditetapkan, yaitu disebelah utara terdapat Desa/Kelurahan Pesu \& Sumberejo Kecamatan Maospati. Sebelah selatan terdapat Desa/Kelurahan Surat Majan \& Kraton Kecamatan Maospati. Sebelah timur terdapat Desa/Kelurahan Surat Majan Kecamatan Maospati. Sebelah Barat terdapat Desa/Kelurahan Kraton kecamatan Maospati.

Secara sosiologis keberadaan Desa Ngujung yang berdekatan dengan kawasan Lapangan Udara Tentara Nasional Indonesia (TNI) Angkatan Udara Iswahyudi, juga berpengaruh terhadap kehidupan masyarakat, di mana tatanan kehidupan masyarakat sudah bernuansa modern seperti dalam kehidupan masyarakat perkotaan, tetapi hanya suasana kehidupan pedesaan juga masih terasa. Hal ini juga banyak berpengaruh terhadap tata pergaulan remaja, yang banyak terpengaruh suasana kehidupan modern seperti di perkotaan, sehingga tingkat kenakalan remaja juga menjadi perhatian pemerintahan desa. Untuk itu adanya program pengabdian kepada masyarakat tentang penyuluhan hukum yang bertema tentang pencegahan kenakalan remaja disambut baik oleh pemerintah desa dan masyarakat Desa Ngujung.

\section{B. Materi Penyuluhan Hukum Pencegahan Kenakalan Remaja}

Adapun materi yang berkaitan dengan penyuluhan hukum tentang pencegahan kenakalan remaja dapat disajikan sebagai berikut :

1. Karakteristik Remaja dari Segi Perkembangan Biologis

Perkembangan ini juga disebut perkembangan fisik. Sarlito Wirawan ${ }^{4}$ dalam M Jupri menyatakan perubahan fisik ke masa remaja sebagai berikut:

Pada anak perempuan

a. Pertumbuhan payudara

b. Tumbuh bulu yang halus dan lurus berwarna gelap di kemaluan

c. Mencapai pertumbuhan ketinggian badan yang maksimal

d. Haid

Pada anak laki-laki

a. Testis(buah pelir) membesar

b. Tumbuh bulu yang halus dan lurus berwarna gelap di kemaluan

c. Awal perubahan suara

d. Ejakulasi(keluar air mani/mimpi basah)

2. Karakteristik Remaja dari Segi Perkembangan Psikis

Ada lima aturan dalam menghadapi masalah remaja, yaitu:

a. Trustworthiness (kepercayaan) yaitu kita harus saling percaya dengan para remaja yang kita hadapi.

\footnotetext{
${ }^{3}$ Soerjono Soekanto, 1986, Beberapa Cara dan Mekanisme Dalam Penyuluhan Hukum, Pradnya Paramita, Jakarta, hal..5

${ }^{4}$ M. Jupri, Analisis Kriminologis dalam menangani Geng Motor, Jurnal e-Jurnal Katalogis, Volume 3 Nomor 12, Desember 2015 hal. 76-84
} 
Website : http://dayamas.unmermadiun.ac.id/index.php/dayamas

b. Genuineness, yaitu maksud yang murni, tidak pura-pura.

c. Empathi, yaitu kemampuan untuk ikut merasakan perasaan remaja.

d. Honesty, yaitu kejujuran

e. Adanya pandangan dari pihak remaja bahwa kita memenuhi keempat unsur diatas.

Berbagai segi dalam kaitannya dengan perkembangan psikologi remaja adalah: Perkembangan konsep diri, Remaja mempunyai posisi pada masa peralihan. Dengan ciri-ciri psikologi sebagai berikut:

a. Berkembangnya ide-ide, gagasan, cita-cita.

b. Kemampuan menilai diri sendiri secara objektif.

c. Mampu menyesuaikan diri dalam masyarakat.

Perkembangan peran social, Masa ini penuh gejolak emosi yaitu di satu pihak ia sudah ingin mandiri sebagai orang dewasa, di lain pihak harus mengikuti orang tuanya. Dan Perkembangan peran seksual Perannya disesuaikan dari jenis kelamin terhadap jenis kelamin lawannya. Kepribadian Androgin adalah kepribadian yang luwes dan mudah menyesuaikan diri.

3. Kenakalan Remaja

Kenakalan Remaja atau Juvenile delinquency, secara etimologis dalam konsep psikologis pengertian Juvenile delinquency berasal dari kata Juvenile yang berarti anak, dan delinquency yang berarti kejahatan. Jadi secara harafiah Juvenile delinquency adalah kejahatan anak. Pasal 1 Undang-Undang Nomor. 3 Tahun 1997 menyatakan bahwa anak nakal adalah:

a. Anak yang melakukan tindak pidana

b. Anak yang melakukan perbuatan yang dinyatakan terlarang bagi anak, baik menurut undang-undang maupun menurut hukum lain yang hidup dan berlaku dalam masyarakat yang bersangkutan.

Juvenile delinquency (kenakalan remaja) ialah perilaku jahat/dursila, atau kejahatan/kenakalan anak-anak muda merupakan patologi secara sosial pada anak-anak dan remaja yang disebabkan oleh satu bentuk pengabaian sosial, sehingga mereka itu mengembangkan bentuk tingkah laku yang menyimpang. Menurut Paul Moedikdo, kenakalan Remaja adalah :

a. Semua perbuatan yang dari orang dewasa merupakan suatu kejahatan bagi anak-anak merupakan kenakalan jadi semua yang dilarang oleh hukum pidana seperti mencuri, menganiaya dan sebagainya.

b. Semua perbuatan penyelewengan dari norma kelompok tertentu untuk menimbulkan keonaran dalam masyarakat.

c. Semua perbuatan yang menunjukkan kebutuhan perlindungan bagi sosial.

Gejala-gejala anak yang mengalami kenakalan remaja adalah :

a. Anak tidak disukai teman-temannyasehingga bersikap menyendiri.

b. Anak sering menghindar dari tanggungjawab mereka di rumah dan di sekolah.

c. Anak sering mengeluh kalau mereka memiliki permasalahan yang mereka sendiri tidak bisa selesaikan.

d. Anak mengalami phobia atau gelisah yang berbeda dengan orang-orang normal.

e. Anak jadi suka berbohong.

f. Anak suka menyakiti teman-temannya.

g. Anak tidak sanggup memusatkan perhatian.

h. Anak suka membolos dari sekolah dan lari dari rumah

i. Anak berperilaku provokatif yang menyimpang

j. Anak bersikap menentang yang berat dan menetap

Menurut Kartini Kartono pengelompokkan kenakalan remaja dalam berbagai tipe yaitu sebagai berikut: ${ }^{5}$

a. Delinkuensi Individual

Kelompok ini mempunyai kelainan jasmaniah dan mental yang dibawa sejak lahir, tingkah laku criminal anak pada kelompok merupakan gejala personal atau individual. Pelaku kenakalan ini tergolong pada tindak pidana dengan kekejaman tanpa motif dan hanya didorong oleh dorongan hati yang sangat kuat.

b. Delinkuensi Situasional

Kenakalan ini dilakukan oleh anak normal tetapi dipengaruhi oleh berbagai kekuatan situasional dan lingkungan yang semuanya memberikan pengaruh menekan memaksa pada pembentukan perilaku buruk/dirangsang pada kebutuhan sesaat.

c. Delinkuensi Sistematik

Kejahatan anak-anak remaja yang diorganisir dan disertai pengaturan yaitu gang. Lingkungan sekitar remaja itu tinggal juga mempengaruhi kejahatan tersebut.

d. Delinkuensi Kumulatif

Situasi sosial dan kondisi kultural buruk yang mempengaruhi terus menerus dan berlangsung berulang kali dapat mengintensifkan perbuatan jahat remaja, sehingga kumulatif sifatnya, yaitu terdapat dimana-mana, tidak hanya di ibu kota Negara saja, tetapi sampai daerah pinggiran pedesaan. (produk konflik budaya hasil dari banyak konflik cultural yang kontroversial)

Delinkuensi remaja yang kumulatif mempunyai ciri-ciri , antara lain:

a. Mengandung banyak dimensi ketergantungan syarat, kegelisahan batin dan keresahan hati para remaja yang kemudian disalurkan secara negatif pada perbuatan jahat. 
Website : http://dayamas.unmermadiun.ac.id/index.php/dayamas

b. Pemberontakan adolensi terhadap kekuasaan orang dewasa dalam usaha menemukan identitas diri lewat tingkah laku yang melanggar norma sosial dan hukum.

c. Penyimpangan seksual disebabkan oleh penundaan saat kawin.

d. Tindakan ekstrim radikal yang dilakukan remaja dengan cara kekerasan, pembunuhan, penculikan.

Jansen dalam Sarlito Wirawan membagi kenakalan remaja ini menjadi 4 jenis:

a. Kenakalan yang menimbulkan korban fisik pada orang lain, misalnya perkelahian, perkosaan, pembunuhan.

b. Kenakalan yang menimbulkan korban materi, misalnya pengerusakan, pencurian, pencopetan.

c. Kenakalan sosial yang tidak menimbulkan korban di pihak lain, misalnya pelacuran, penyalahgunaan obat, hubungan seks sebelum menikah.

d. Kenakalan melawan status, misalnya perbuatan mengingkari status sebagai pelajar dengan cara membolos, minggat dari rumah, membantah perintah orang tua.

Pembagian lain dari kenakalan remaja berdasarkan ciri kepribadian yang defek atau ciri kepribadian yang rusak, antara lain:

a. Delinkuensi Terisolir, Kejahatan didorong oleh faktor:

1) Motivasi kecemasan dan konflik batin yang tidak dapat diselesaikan, dipengaruhi oleh keinginan meniru dengan gangnya.

2) Sudah masuk dalam gang sejak kecil dan mulai terbiasa dengan aktivitas di dalamnya.

3) Berasal dari keluarga yang broken home, lalu ikut dalam lingkungan anak criminal untuk memuaskan kebutuhannya.

4) Tidak mendapat didikan tentang kedisiplinan yang teratur.

b. Delinkuensi Neurotik, Anak delinkuensi ini menderita gangguan kejiwaan yang cukup serius, misalnya kecemasan, merasa selalu tidak aman, merasa terancam, tersudut dan terpojok, merasa bersalah atau berdosa.

c. Delinkuensi Psikopatik, Delinkuensi ini dilakukan oleh mereka dengan tanpa motif apapun juga, sikapnya aneh, sangat kasar, kurang ajar, perbuatannya sering ganas sadis, suka menyakiti hati orang lain, suka menyakiti jasmani orang lain. Penjahat delinkuen ini dikategorikan penjahat paling berbahaya.

d. Delinkuensi Defek Moral, Ciri delinkuensi ini adalah selalu melakukan perbuatan a-sosial, karena remaja ini tidak mampu mengendalikan dan mengatur dirinya. Remaja ini biasanya menjadi penjahat yang sukar diperbaiki(Residivis) yang melakukan kejahatan karena didorong oleh naluri rendah, impuls dan kebiasaan primitif.

Jenis-jenis Kenakalan Remaja, seperti yang sudah diuraikan di atas, maka kenakalan remaja yang dimaksud di sini adalah perilaku yang menyimpang dari atau melanggar hukum. Jensen membagi kenakalan remaja menjadi 4 jenis yaitu: ${ }^{6}$

a. Kenakalan yang menimbulkan korban fisik pada orang lain; perkelahian, perkosaan, perampokan, pembunuhan dan lainlain.

b. Kenakalan yang menimbulkan korban materi pencurian.

c. Kenakalan sosial yang tidak menimbulkan korban di pihak orang lain;

d. pelacuran, penyalahgunaan obat-obatan terlarang,hubungan seks pranikah.

e. Kenakalan yang melawan status, misalnya mengingkari status anak sebagai pelajar dengan membolos, melanggar disiplin sekolah.

Langkah- langkah untuk mengatasi dan mencegah kenakaln remaja antara lain dapat dilakukan :

1. Orang tua harus memberikan perhatian, pengawasan, dan kasih sayang yang lebih kepada anak dan juga orang tua harus membuka komunikasi dua arah ( mendengarkan dan terbuka) kepadan anak.

2. Memberikan kebebasan yang ada batasannya.

3. Memberikan pendidikan agama kepada remaja.

4. Mengajari remaja agar tidak mudah terpengaruh oleh pergaulan yang negatif.

5. Memberikan kegiatan- kegiatan yang positif kepada remaja agar remaja sibuk dan tidak memiliki waktu untuk melakukan hal-hal yang negatif.

6. Memberikan pengetahuan tentang Undang-Undang yang mengatur tentang kenakalan remaja dan sanksinya.

\section{IV.KESIMPULAN}

Masa remaja merupakan masa dimana seorang individu mengalami peralihan dari satu tahap ke tahap berikutnya dan mengalami perubahan baik emosi, tubuh, minat, pola perilaku, dan juga penuh dengan masalah-masalah. Oleh karenanya, remaja sangat rentan sekali mengalami masalah psikososial, yakni masalah psikis atau kejiwaan yang timbul sebagai akibat terjadinya perubahan sosial. Juvenile delinquency (kenakalan remaja) ialah perilaku jahat/dursila, atau kejahatan/kenakalan anak-anak muda merupakan patologi secara sosial pada anak-anak dan remaja yang disebabkan oleh satu bentuk pengabaian sosial, sehingga mereka itu mengembangkan bentuk tingkah laku yang menyimpang. Sedangkan pengelompokkan kenakalan remaja dalam berbagai tipe yaitu sebagai berikut yaitu Delinkuensi Individual, Delinkuensi Situasional, Delinkuensi Sistematik dan Delinkuensi Kumulatif.

Untuk itu upaya pencegahan kenakalan remaja dapat dilakukan antara lain : (1) Orang tua harus memberikan perhatian, pengawasan, dan kasih sayang yang lebih kepada anak dan juga orang tua harus membuka komunikasi dua arah (mendengarkan

\footnotetext{
${ }^{6}$ H Herlina, A Kosasih, Penanggulangan kenakalan remaja di SMP Daarut Tauhid Boarding School, Jurnal Sosietas, 2016 dalam ejournal.upi.edu
} 
Website : http://dayamas.unmermadiun.ac.id/index.php/dayamas

dan terbuka) kepadan anak, (2) Memberikan kebebasan yang ada batasannya, (3) Memberikan pendidikan agama kepada remaja, (4) Mengajari remaja agar tidak mudah terpengaruh oleh pergaulan yang negative, (5) Memberikan kegiatan- kegiatan yang positif kepada remaja agar remaja sibuk dan tidak memiliki waktu untuk melakukan hal-hal yang negative dan (6) Memberikan pengetahuan tentang Undang-Undang yang mengatur tentang kenakalan remaja dan sanksinya.

\section{DAFTAR PUSTAKA}

Atmasasmita, Romli. 1993. Problem Kenakalan Anak-anak Remaja (Yuridis Sosial Kriminologi), Armico, Bandung.

Darajat, Zakiah. 2014 .Problema Remaja diIndonesia, Bulan Bintang, Jakarta : Bulan Bintang.

H Herlina, A Kosasih, Penanggulangan kenakalan remaja di SMP Daarut Tauhid Boarding School, Jurnal Sosietas, 2016 dalam ejournal.upi.edu

M. Jupri, Analisis Kriminologis dalam menangani Geng Motor, Jurnal e-Jurnal Katalogis, Volume 3 Nomor 12, Desember 2015

Nurmalisa, MM Adha, 2016, Peran Lembaga Sosial Terhadap Pembinaan Moral Remaja Di Sekolah Menengah Atas, Jurnal Ilmiah Pendidikan Pancasila dalam journal2.ums.ac.id

Soerjono Soekanto, 1986, Beberapa Cara dan Mekanisme Dalam Penyuluhan Hukum, Pradnya Paramita, Jakarta. 